\title{
Sistema de Drenagem Pluvial: um estudo de caso sobre a determinação de vazões para o dimensionamento dos dispositivos em uma obra de implantação de produção
}

\section{de ferro}

Pluvial Drainage System: a case study on the determination of flows for the dimensioning of devices

in an iron production implantation work

Sistema de Drenaje Pluvial: un estudio de caso sobre la determinación de flujos para el

dimensionamiento de dispositivos en un trabajo de implantación de producción de hierro

Recebido: 23/11/2021 | Revisado: 30/11/2021 | Aceito: 01/12/2021 | Publicado: 12/12/2021

Barbara Marques Carneiro
ORCID: https://orcid.org/0000-0001-7606-0905
Faculdade de Engenharia de Minas Gerais, Brasil
E-mail: barbaramarquesc@ outlook.com
Keven Costa Barbosa Fajardo
ORCID: https://orcid.org/0000-0001-7564-2276
Faculdade de Engenharia de Minas Gerais, Brasil
E-mail: keven.cbf@ gmail.com
Michelle Marcuci Fonseca
ORCID: https://orcid.org/0000-0001-6174-3754
Faculdade de Engenharia de Minas Gerais, Brasil
E-mail: michellemarcuci@ gmail.com
Paulo Mário Cruz de Freitas
ORCID: https://orcid.org/0000-0001-9917-6070
Faculdade de Engenharia de Minas Gerais, Brasil
E-mail: pmariocf@ gmail.com

\section{Resumo}

O presente estudo considera a realidade de uma mineradora denominada MinerXYZ e a descrição da memória de cálculo para o dimensionamento do projeto do sistema de drenagem pluvial. Parte-se do projeto de drenagem da Mina chamada S-1 voltando-se ao adequado direcionamento do fluxo superficial ao longo dos platôs e dos acessos, com o uso de dispositivos de drenagem, de forma a direcioná-los para as bacias de decantação ou local de desague seguro. O objetivo desse estudo foi conhecer as principais etapas para se executar um projeto de drenagem pluvial com base no estudo de caso em uma mineradora. A metodologia é descritiva em que optou pelo estudo de caso em uma mineradora de minério de ferro. Como resultados pôde-se verificar que a eficiência do sistema de drenagem pluvial para a Mina SII mostrouse com resultado conclusivo, respeitando o período de observação adequado, que fundamenta a construção dos elementos estruturantes do sistema de drenagem para esta unidade e avaliando a sua dinâmica no período de maior intensidade de precipitações. Concluiu-se pela a importância e a necessidade de se contar com um projeto de sistema de drenagem, considerando alguns ecursos necessários já existente na Mina SIII com um alinhamento para elaboração e adequação da atividade na rotina do empreendimento.

Palavras-chave: Drenagem; Pluvial; Mineração; Projeto.

\begin{abstract}
The present study considers the reality of a mining company called MinerXYZ and the description of the calculation memory for the dimensioning of the rainwater drainage system project. It starts with the drainage project for the Mine called S-1, focusing on the adequate direction of the surface flow along the plateaus and accesses, with the use of drainage devices, to direct them to the decantation basins or safe drain site. The objective of this study was to know the main steps to carry out a rainwater drainage project based on a case study in a mining company. The methodology is descriptive in that it opted for the case study in an iron ore mining company. As a result, it could be verified that the efficiency of the rainwater drainage system for Mine SI proved to be a conclusive result, respecting the appropriate observation period, which underlies the construction of the structural elements of the drainage system for this unit and evaluating its dynamics in the period of greatest rainfall intensity. It was concluded by the importance and necessity of having a drainage system project, considering some necessary resources already existing in Mine SI with an alignment for the elaboration and adequacy of the activity in the enterprise's routine.
\end{abstract}

Keywords: Drainage; Rainwater; Mining; Project. 


\begin{abstract}
Resumen
El presente estudio considera la realidad de una empresa minera denominada MinerXYZ y la descripción de la memoria de cálculo para el dimensionamiento del proyecto del sistema de drenaje pluvial. Se inicia con el proyecto de drenaje de la Mina denominado S-1, enfocándose en la adecuada dirección del flujo superficial a lo largo de las mesetas y accesos, con el uso de dispositivos de drenaje, con el fin de dirigirlos a las cuencas de decantación o drenaje seguro. El objetivo de este estudio fue conocer los principales pasos para llevar a cabo un proyecto de drenaje de aguas pluviales a partir de un estudio de caso en una empresa minera. La metodología es descriptiva ya que se optó por el estudio de caso en una empresa minera de hierro. Como resultado, se pudo verificar que la eficiencia del sistema de drenaje pluvial de la Mina SII resultó ser un resultado concluyente, respetando el período de observación adecuado, que subyace en la construcción de los elementos estructurales del sistema de drenaje de esta unidad y evaluando su dinámica en el período de mayor intensidad de lluvia. Se concluyó por la importancia y necesidad de contar con un proyecto de sistema de drenaje, considerando algunos recursos necesarios ya existentes en Mina SIII con una alineación para la elaboración y adecuación de la actividad en la rutina de la empresa.
\end{abstract}

Palabras clave: Drenaje; Agua de lluvia; Minería; Proyecto.

\title{
1. Introdução
}

Um sistema de drenagem (tubulação de drenagem ) inclui toda a tubulação dentro de instalações públicas ou privadas, que transporta rejeitos , água da chuva ou outros resíduos líquidos para um ponto legal de descarte, mas não inclui a rede de um sistema ou uma estação de tratamento ou eliminação de rejeitos (Loura, 2011).

Para realizar as suas atividades de extração, processamento e expedição de minérios na mina S-1, é necessário contar com a elaboração de um projeto técnico de sistema de drenagem, com o intuito de promover o escoamento das águas superficiais pluviais. Nesse sentido, considera-se a realidade de uma mineradora denominada MinerXYZ e a descrição da memória de cálculo para o dimensionamento do projeto do sistema de drenagem pluvial.

Considera-se a realidade de uma mineradora denominada MinerXYZ e a descrição da memória de cálculo para o dimensionamento do projeto do sistema de drenagem pluvial. O projeto de drenagem da Mina chamada S-1, refere-se ao adequado direcionamento do fluxo superficial ao longo dos platôs e dos acessos, com o uso de dispositivos de drenagem, de forma a direcioná-los para as bacias de decantação ou local de desague seguro. Quais os cuidados a serem observados na execução de um projeto técnico de drenagem pluvial para uma planta de exploração de minério? O objetivo geral foi conhecer as principais características para se executar um projeto de drenagem pluvial com base no estudo de caso em uma mineradora.

Faz-se necessário entender a dinâmica do Sistema de Drenagem Pluvial para o contexto das mineradoras, do processo executivo recorrentes no mesmo, assim como é de a máxima importância abordar as possibilidades de recuperação, que é, de certa maneira, uma forma de contribuir para um melhor nível de qualidade da gestão dos rejeitos do processo produtivo e de segurança para trabalhadores e da própria população, por estarem mais expostas nas zonas de risco (Langhammer, 2019).

\section{Desenvolvimento}

\subsection{Sistema de drenagem para plantas de exploração de minério de ferro}

A trajetória de evolução da mineração brasileira é resultado da crescente demanda mundial por minérios e, também, pelo avanço e redução do custo da tecnologia dos equipamentos. Considerando que estes aspectos têm viabilizado a execução de expressivos projetos mineiros, que sua vez alcançam, de maneira significativa, elementos não observados antes, como as relações estéril-minério mais prejudiciais.

Tucci (2013) cita que os referidos componentes refletem em montantes de capital a serem investidos até o momento em que se alcança o minério de interesse, permitindo a análise do retorno deste investimento. Messe sentido é que Kipper (2015) considera a demanda por estudo de planejamento da lavra buscando a otimização da relação entre a economia global do projeto ou empreendimento e os riscos que estão associados às suas decisões de projeto. Dentre várias análises que precisam ser feitas, tem-se o sistema de drenagem específico a ser adotado para as plantas de exploração mineral, como considera Marques (2019) 
e, sendo este, o foco deste estudo. É preciso contar com projetos cada vez, mas detalhados, considerando todos os fatores geológicos e geotécnicos de estabilidade de segurança e, também, de economicidade do futuro empreendimento.

Neste contexto é que Sampaio (2011) destaca os estudos de drenagem assumindo uma função determinante, não apenas nos aspectos subsidiadores das decisões a serem tomadas sobre a planta de exploração e beneficiamento, mas, também com relação a estabilidade dos taludes. E, por consequência, no planejamento global da mobilização das águas envolvidas em sítio em que dará a instalação da planta em questão.

A problemática da água superficial advinda da precipitação ou de outras fontes envolve a coleta e direcionamento para canais de escoamento ao redor da estrutura. Contempla ainda, a condução por drenagem interna. De acordo com os aspectos do local em que se encontra instalada o sistema de drenagem (Araújo, Schuster; Lima, 2011).

De acordo com Costa, Samuel-Rosa e Anjos (2018), o sistema de drenagem superficial precisa abarcar a execução de canais periféricos buscando à interceptação das águas pluviais vindas dos arredores externos da pilha e o redirecionamento dessas até o sistema extravasador final. Nas palavras de Gonçalves (2018, p.44), lê-se que "os sistemas de drenagem em uma mina a céu aberto possuem basicamente três objetivos principais: Interceptar a entrada de água, reduzir danos na estrutura interna e remover a água do interior da cava".

Nos chamados sistemas de isolamento e escoamento, Teixeira Júnior (2015) menciona tratar-se do que é comumente escolhido para impedir o fluxo de água para dentro da cava, são formadas para valas e diques ao seu redor. De acordo com Polat e Uysal (2018), o referido fluxo então tem redirecionamento para o fundo da cava (bottom pit) mediante de canaletas construídas nos pés das bancadas ou por tubulações. Na citada etapa é essencial evitar que a água escoe pela crista da bancada, e assim, se evita o processo de erosão excessiva, também conservando suas características geotécnicas.

\subsection{Metodologia de projeto de drenagem}

O procedimento relacionado ao projeto de drenagem, geralmente envolve as mesmas etapas e os mesmos estudos. A fim de melhor descrever cada um dos elementos que precisam ser observados e o que deve ser considerado, apresenta-se a síntese baseada nos estudos de Barros (2000); Franco (2004); Castro et al., (2009) e David (2014).

De acordo com Franco (2004), os estudos topográficos precisam ser iniciados pela delimitação da região em que as águas precipitadas concorrem, de algum modo, para área da futura cava. Trata-se de uma delimitação da região mediante divisores de água, em que se tem a instalação da obra. Silwamba e Chileshe (2015) destacam que são exigidas plantas topográficas em escalas adequadas 1:10.000 ou 1:25.000, ou contar com fotografias aéreas.

David (2014) esclarece que é necessário contar com a identificação dos percursos naturais de drenagem e as possíveis erosões que poderão servir como futuros canais receptores de águas movimentadas de outras áreas. Simultaneamente, é preciso identificar mediante as análises das plantas topográficas dos sítios mais propícios para instalação de reservatórios para o abastecimento de água para diferentes fins, a contar o consumo humano industrial.

Segundo Thompson et al., (2019), os reservatórios para decantação de rejeitos da usina de beneficiamento do minério; a instalação de corpos de bota fora para o estéril, dentre outros, relaciona-se com a localização dos referidos elementos, não constituindo o projeto de drenagem, de fato, mas, estando relacionados a ele. Rock et al., (2020) destacam as características, tais como a disposição geral dos cursos naturais e artificiais da água, bem como o controle de poluição dos mananciais e a estabilidade de taludes de aterros de bota-fora, dentre outros.

No que se refere à hidrologia, Castro et al., (2009) esclarecem que, desde o instante em que se dá início as pesquisas de ocorrências minerais, é preciso voltar se as instalações de pluviômetros na área, dar início a um acompanhamento diário e sistemático das chuvas. É possível considerar a participação de instituições oficiais e de empresas da região para acompanhamento pluviométrico de um intervalo de tempo maior. 
Com o levantamento da totalidade dos elementos que podem implicar no estudo do regime de chuvas ainda mediante as estações pluviométricas relativamente distantes para além dos registros para a área de interesse. Gonçalves (2018) cita que, em uma perspectiva futura, a totalidade dos dados precisa ser tratada de maneira estatística com médias diária, mensal e anual, dentre outras, para que se possa proceder com tomadas de decisão mais assertiva.

Em relação ao projeto de drenagem o estudo do regime de chuvas inclui necessariamente a sazonalidade climática apontando não apenas os meses de maior intensidade de chuvas do ano na região, mas também indicando as metas diárias e mensais da estação chuvosa além dos períodos de concentração de chuvas dentre outros os referidos elementos podem fundamentar os projetos de sistemas de recalque, indicando também, a programação da instalação e manutenção destes.

\subsection{Estudos de projeto}

Sobre os estudos de projeto David (2014) detalha que os condicionantes de maior peso no processo decisório em relação a viabilidade da lavra se associam as pesquisas da forma da jazida da natureza do minério, da maneira que ocorrerá o beneficiamento dentre outros, dado que o investidor, geralmente, está preocupado com os teores e reservas recuperáveis do mineiro.

Em relação aos estudos de drenagem, Barros (2000) menciona que eles não influenciarão tais decisões, uma vez que não atingem de maneira direta, a relação minério estéril. As pesquisas fundamentam as análises de risco associados ao empreendimento. E, quando se traz os aspectos da geometria da futura cava, tem-se uma associação com os volumes recuperáveis de minério em que as ponderações relacionadas ao a movimentação das águas tem definição dada em termos de projeto.

Castro, Barros e Pereira (2009) explicam ainda, que os estudos de projetosmineiros, são realizadosem etapas sucessivas de crescente detalhamento. Assim sendo, os estudos de drenagem de cava a céu aberto precisam ser também progressivamente pormenorizados, ao passo em que se tem novas informações no decorrer do desenvolvimento deste empreendimento. Considerando os estudos de Barros (2000); Franco (2004); Castro et al., (2009) e Silveira (2014), é possível correlacionar que as informações básicas relacionadas aos projetos de drenagem podem ser classificadas em dois segmentos a citar: baseando-se em estudos topográficos citados anteriormente e no arranjo geral da mina, precisam ser definidas as zonas de contribuição que poderão ser realocadas para caminho de drenagem externos a escavação.

Barros (2000) explica tratar-se de zonas em que a contribuição pode ingressar na escavação e zonas que precisam ser esgotadas por recalque. Esta última, conta com arranjo geral da mina, fornecendo as alturas de elevação correspondentes. Baseando-se nos estudos hidrológicos acerca do regime de chuvas, escoamento superficial, infiltração, evapotranspiração e, também, nos estudos geológicos, geotécnicos e hidrogeotécnicos acerca da permeabilidade, zonas de recarga, regime de percolação, drenabilidade, dentre outros. É preciso delimitar as contribuições da precipitação pluviométrica e da água subterrânea para cada zona em questão.

\section{Metodologia}

Quanto aos fins, o estudo pode ser classificado como pesquisa exploratória e descritiva, visto que a escolha se deu por estar alinhado à definição dada por Gil (2009), referindo-se às pesquisas que são adequadas à descrição teórica e expositiva dos assuntos a serem apresentados e por possibilitarem a consecução dos objetivos.

Foi descrita por ser conduzido para melhor compreensão do problema existente em relação ao adequado projeto de drenagem pluvial para a mineração. É descritivo também por permitir observar, registrar, analisar e correlacionar fatos ou fenômenos variáveis sem manipulá-los, sem qualquer interferência dos pesquisadores. 
A pesquisa foi exploratória por ter permitido investigar um problema que não está claramente definido como é o caso de saber os detalhes e as singularidades do projeto de drenagem pluvial para a Mina S 1.

Quanto aos meios, se trata de uma pesquisa bibliográfica e estudo de caso considerando-se o local de trabalho de um dos integrantes. De início, é uma revisão bibliográfica por considerar a seleção do conhecimento científico prévio sobre um determinado tema para que se possam definir os objetivos de um projeto de pesquisa como assinala

Por meio de uma abordagem qualitativa, foram analisados os critérios de maior impacto de um projeto de drenagem pluvial no contexto de uma mina de extração de minério de ferro para melhor compreensão das variáveis a serem trabalhadas, as condições do local e a melhoria que pode ser alcançada no dimensionamento dos projetos de drenagem pluvial para este contexto,

Na pesquisa deste projeto foram realizadas 6 visitas técnicas em março de 2021 como um dos procedimentos de pesquisa na coleta de dados, que permitem registros fotográficos, diários de visitas, observação não participante e entrevistas livres (conversas informais) como engenheiros responsáveis pelo projeto de drenagem pluvial, relacionadas às principais etapas para se executar um projeto de drenagem pluvial, com base no estudo de caso em uma mineradora.

\section{Apresentação e Análise dos Resultados}

A Mina S III faz parte de um segundo projeto de cobre elaborado por uma das maiores mineradoras no Brasil. A referida Usina está situada em Marabá, sudeste paraense, e deu início a operação em novembro de 2012. O citado empreendimento, cuja capacidade nominal é de cerca e 100 mil toneladas anuais de cobre em concentrado. Com a expansão da operação, o Mina S II, a capacidade de produção do empreendimento foi duplicada para 200 mil toneladas por ano do produto.

$\mathrm{O}$ projeto $\mathrm{S}$, em si, contempla a operação integrada de lavra a céu aberto, beneficiamento, transporte e embarque. O escoamento da produção é realizado por rodovia, da mina até terminal ferroviário da Mineradora em Parauapebas (PA), sendo transportada pela Estrada de Ferro Carajás até o terminal marítimo de Ponta da Madeira (MA).No ano de 2013, a unidade respondeu por 65 mil toneladas de cobre contido em concentrado, no ano seguinte de 2014, respondendo pela produção de 40,8 mil toneladas do produto. O projeto S é representado na Figura 1:

Figura 1 - Visão de parte do Projeto S I

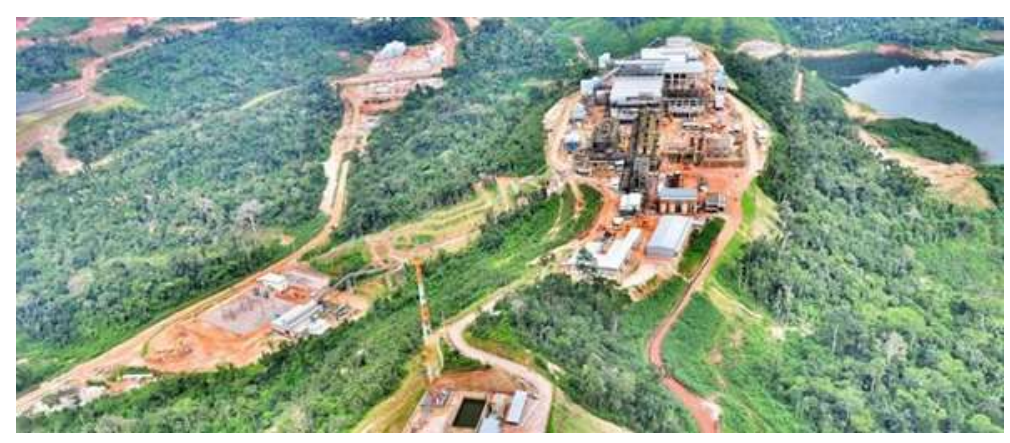

Fonte: Dados primários da pesquisa (2021).

No referido cenário destaca-se a S, é considerado maior projeto de cobre de uma das maiores mineradoras em operação no Brasil. A empresa explora a mina S, em Marabá, no Pará, com reserva estimada em 1,2 bilhão de toneladas de minério de cobre. Trata-se do maior depósito de cobre do país e reponde por $48 \%$ do cobre produzido pela citada mineradora no mundo, sendo essencial para competitividade e fortalecimento do negócio. 
O minério extraído em Marabá é exportado, em sua grande parte, para países europeus. Antes, o minério é submetido a um processo de britagem, em que seu tamanho reduzido, por rolos que o fragmentam e por demais etapas que desencadeiam um concentrado de cobre. O referido concentrado é transformado em placas e usado pela indústria. Buscando pela manutenção da competitividade internacional e o aumento da capacidade de beneficiamento da unidade, foi aportado um investimento de 1,1 bilhão de dólares no projeto S III. Trata-se da segunda expansão da mina desde o começo de suas operações em 2012 e, dentre as obras que tem duração de três anos, contemplam-se as de drenagem pluvial na mina.

Vale destacar que, no primeiro semestre de 2022, a mineradora já colocará em funcionamento o projeto de produção de cobre, o S III, com perspectiva de operação de 12 milhões de toneladas do minério. A expansão, do tipo técnico "brownfield" diz respeito a estratégia de aumentar a capacidade de processamento do complexo. O Projeto S, quando foi construído, considerou duas plantas e o S III vai aumentar a produção em 12 milhões de toneladas de minério que poderão ser processadas. O que representa, além das 24 milhões de toneladas de cobre já são produzidas pelas duas primeiras plantas, a inserção de mais 12 milhões. Além do cobre, também são produzidos minérios como ouro e prata, subprodutos do cobre. A Figura 2 mostra uma visão do Projeto da Minas SI especificamente em relação à drenagem pluvial.

Figura 2 - Projeto Salobo I - Drenagem Pluvial.

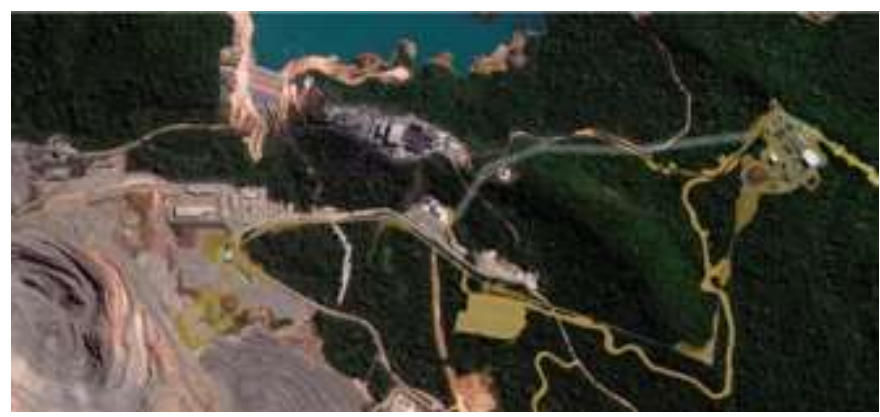

Fonte: Dados primários da pesquisa (2021).

O empreendimento denominado Drenagem Pluvial S III implantou o sistema de drenagem pluvial na mina e rede para interceptação e afastamento do local. Foram realizadas obras de drenagem, com galeria celular, rede tubular de concreto dn de $400 \mathrm{~mm}$ a $100 \mathrm{~mm}$, rede tubular dispositivos de concreto de drenagem - coleta de água da chuva para desaguar no local certo ponto de desague seguro (bacia de decantação) de rede de drenagem, beneficiando a dinâmica da Mina S I. Porém, uma problemática comum em obras de drenagem também se fazia presente neste caso: conduzir as intervenções estruturantes de forma prevista em projeto e buscar um plano de ação para que conservasse as melhorias proporcionadas como citado por Tucci (2013).

O estudo permite compreender os aspectos principais da Mina S III sob a ótica da rede de macrodrenagem para captação de águas pluviais e dos problemas frequentes e graves de inundação. Não obstante, pode-se compreender a intensificação dos processos de erosão, o transporte e a deposição de sedimentos, bem como o lançamento de rejeitos nos canais promoveram uma aceleração significativa do processo de desgaste estrutural dos canais em concreto como reforça Teixeira Júnior (2015).

Não foram aceitos elementos estruturais que não estejam previstos em projeto e o responsável pelo projeto levou em consideração as soluções de drenagem - micro e macrodrenagem - existentes e ou planejadas na Mina S III. Os parâmetros para os cálculos hidrológicos e hidráulicos dos projetos de drenagem são adotados pela equipe responsável, salvo indicação diversa constante nesta diretriz ou indicação específica para o projeto por técnicos do Projeto da Mina S III. Para o conhecimento do regime de chuvas na região, foram coletados dados da estação meteorológica de Carajás - N5 mostrado na Tabela 1: 
Tabela 1 - Estudo hidrológico da região de Marabá.

\begin{tabular}{|c|c|c|c|c|c|}
\hline \multicolumn{6}{|c|}{ Intensidade de Precipitação $(\mathrm{mm} / \mathrm{h})$} \\
\hline & 10 & 15 & 25 & 50 & 100 \\
\hline$P(24 h)$ & 7,64 & 8,35 & 9,22 & 10,39 & 11,55 \\
\hline$P(12 h)$ & 12,99 & 14,19 & 15,67 & 17,66 & 19,64 \\
\hline$P(10 h)$ & 15,04 & 16,43 & 18,15 & 20,45 & 22,73 \\
\hline $\mathbf{P}(\mathbf{8 h})$ & 17,89 & 19,53 & 21,58 & 24,31 & 27,03 \\
\hline $\mathbf{P}(6 h)$ & 22,01 & 24,04 & 26,55 & 29,92 & 33,26 \\
\hline $\mathbf{P}(\mathbf{1 h})$ & 77,05 & 84,14 & 92,94 & 104,73 & 116,43 \\
\hline $\mathbf{P}(30$ min $)$ & 114,03 & 124,53 & 137,55 & 155,00 & 172,31 \\
\hline$P(25$ min $)$ & 124,52 & 135,99 & 150,20 & 169,25 & 188,17 \\
\hline $\mathbf{P}(20$ min $)$ & 138,55 & 151,31 & 167,12 & 188,32 & 209,36 \\
\hline$P(15$ min $)$ & 159,65 & 174,35 & 192,57 & 216,99 & 241,24 \\
\hline$P(10$ min $)$ & 184,73 & 201,74 & 222,83 & 251,09 & 279,15 \\
\hline$P(5$ min $)$ & 232,63 & 254,05 & 280,60 & 316,19 & 351,52 \\
\hline
\end{tabular}

Fonte: Dados primários da pesquisa (2021).

Para fins de elaboração dos projetos de microdrenagem, nos lançamentos em rede pública, seguiu-se na execução do levantamento topográfico da rede existente e apresentar estudos que comprovem que a rede existente comporta a vazão do lançamento do empreendimento como menciona Awasthi (2019). Em situações em que se tenha necessidade de incremento à rede existente, deve-se projetar a mesma até o ponto de compatibilização, ficando, em princípio, sob a responsabilidade do empreendedor a referida complementação, mesmo que sejam extrapolados os limites do empreendimento como sugere Kipper (2015).

Assim, o estudo hidrológico foi apresentado em planta com delimitação das bacias e sub-bacias e planilhas de cálculo das vazões, indicando com nitidez as bacias de contribuição e todos os parâmetros de cálculo utilizados. As redes de microdrenagem em que se adotou um período de recorrência de 10 anos. Nas canalizações (trocar) e redes de macrodrenagem deve-se adotar período de recorrência mínimo de 25 anos e o coeficiente volumétrico mínimo (C2) de 0,80 nas áreas de Minas. Na Figura 3 pode-se ver a localização do posto pluviométrico N5 da Mina S I:

Figura 3 - Posto pluviométrico N5 - Mina S I.

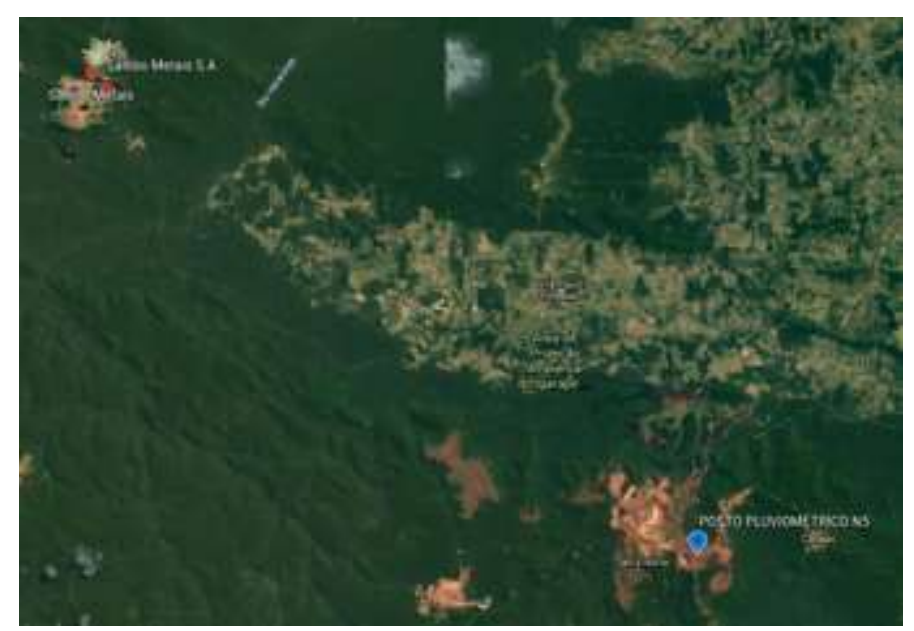

Fonte: Dados primários da pesquisa (2021).

O projeto das redes de drenagem são melhor apresentados nas seguintes etapas, juntamente com as memórias de cálculos sugeridos por David (2014). Planta geral de situação do projeto de drenagem com todas as redes projetadas. Pranchas com o projeto específico de cada rede em planta e perfil, indicando nos rodapés todos os parâmetros hidráulicos das redes conforme 
padrão Mina S I. O Estudo Hidrológico realizado objetivou a pesquisa dos elementos disponíveis representativos da pluviometria local, além da definição dos parâmetros de cálculo das descargas máximas prováveis das bacias hidrográficas que contribuem em todas as vias deste complexo viário como também destaca Gonçalves (2018).

A vazão máxima de projeto definida a jusante da bacia de contribuição é de 15,211 m3/s. Para as características geométricas das bacias de contribuição, foram utilizadas plantas de restituição aerofotogramétrica na escala de $1: 2000$ e um minucioso estudo local. Em relação aos períodos de recorrência, tem-se: obras de drenagem superficial: 5 anos; redes coletoras: 10 anos e canalização de 25 anos. Na determinação vazão de projeto, esta foi definida a jusante da bacia de contribuição é de $15,211 \mathrm{~m} 3 / \mathrm{s}$. Para as características geométricas das bacias de contribuição, foram utilizadas plantas de restituição aerofotogramétrica na escala de $1: 2000$ e um minucioso estudo local. Adotando o Método Racional - Bacias com área até 0,5km².

O coeficiente de deflúvio quantifica o grau de absorção de água pela superfície onde ocorre a precipitação, representando quantos \% do volume precipitado será escoado efetivamente como mostra o Quadro 1:

Quadro 1 - Valores para o coeficiente de deflúvio.

\begin{tabular}{|c|c|}
\hline $\begin{array}{c}\text { Coeficiente de deflúvio } \\
\text { Terreno natural }\end{array}$ & 0,45 \\
\hline Xisto fino & 0,50 \\
\hline Talude gramado & 0,65 \\
\hline Revestimento primário & 0,70 \\
\hline Pavimento flexível/rígido & 0,90 \\
\hline
\end{tabular}

Fonte: Dados primários da pesquisa (2021).

Importante destacar que nas fases iniciais do ciclo hidrológico, maior atenção foi dada a questão do escoamento superficial para a Mina SI, dado que se refere a uma etapa que verificou a ocorrência e transporte da água na superfície terrestre, sendo os estudos hidrológicos indicando as possibilidades de aproveitamento da água superficial e à proteção em relação aos fenômenos desencadeados pelo seu deslocamento como foi citado por Silveira (2014).

Assim sendo, como frisado por Castro, Barros e Pereira (2009) o coeficiente de escoamento superficial acima apresentado também chamado de coeficiente de deflúvio, ou ainda, coeficiente de "runoff", foi dado pela razão entre o volume de água escoado superficialmente e o volume de água precipitado. Deste modo, o coeficiente se aplica a ocorrência de chuva isolada ou a um intervalo de tempo em que diversas chuvas ocorreram.

Com a determinação do coeficiente de "runoff" para chuvas intensas, com sua duração, se tem a possibilidade de determinar o escoamento superficial de demais precipitações de intensidades distintas, dede que se tenha igual duração.

No dimensionamento da rede de drenagem da Mina S III, foram considerados os parâmetros hidrológicos, dentre eles o Tempo de Retorno ( $\mathrm{T}$ ) -período que um determinado evento hidrológico é igualado ou superado pelo menos uma vez como visto em Barros (2000). O dimensionamento das obras de Drenagem de S III foi efetuado para atendimento às vazões de projeto associadas aos períodos de retorno indicados no Quadro 2: 
Quadro 2 - Valores para o TR.

\begin{tabular}{|l|c|}
\hline ESTRUTURA & TR (Anos) \\
\hline Drenagem Superficial & 10 \\
\hline Bueiro Simples & 15 \\
\hline Bueiro Celular & 25 \\
\hline Canal do Rejeito & 25 \\
\hline Bacias de Decantação & 25 \\
\hline Caixas de Retenção & 25 \\
\hline
\end{tabular}

Fonte: Dados primários da pesquisa (2021).

Já em relação ao Tempo de concentração, este considerou o tempo em que leva para que toda a bacia considerada contribua para o escoamento superficial na seção estudada, ou ainda é o tempo para que a gota de água que cai no ponto mais distante chegue até a seção que define o limite da bacia também citado por David (2014).

A rede de drenagem da Mina S I considerou todos os estudos realizados no local e o próprio arranjo da planta da mina com suas características geográficas, climáticas e topográficas como sugere Lin et al., (2020). Basicamente os problemas que foram enfrentados com relação à proximidade do período chuvoso comprometendo o cronograma de obra.

Como se trabalhou basicamente toda a área da Mina S III, também foi realizado um trabalho junto aos trabalhadores e moradores do entorno que podem ser atingidos diretamente, pois foi empregado com equipamentos pesados, muitas pessoas transitaram pelo local e eles podem se sentir incomodados com a presença da equipe técnica.

A rede de esgotamento foi implantada nos dois lados da drenagem que também se tem a bacia de decantação de lavagem dos pisos próxima a área de operação de britagem e outra bacia de decantação situada próxima ao acesso principal da Mina S I, em que se tem a usina principal próxima ao Córrego do Mamão como mostra a Figura 4:

Figura 4 - Visão geral do projeto de drenagem da Mina S I.

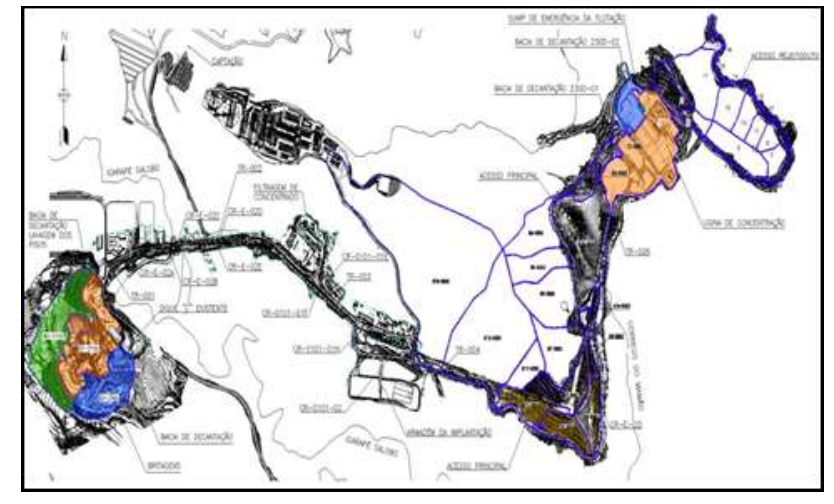

Fonte: Dados primários da pesquisa (2021).

Na Figura 5 se tem o destaque da área comum da usina de concentração: 
Figura 5 - Visão dos elementos próximos a usina de concentração da Mina SI.

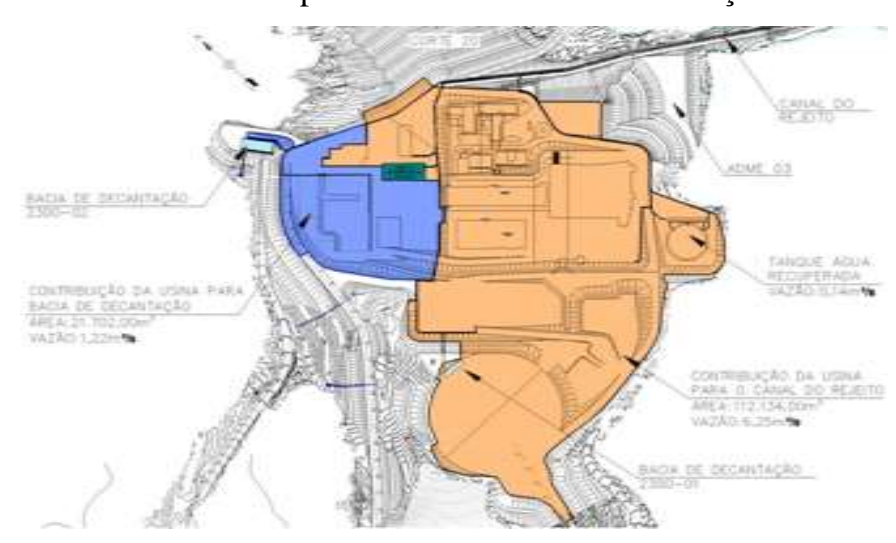

Fonte: Dados primários da pesquisa (2021).

Observa-se a disposição da bacia de sedimentação, tanque de decantação ou tanque de decantação é uma estrutura de terra ou concreto que usa sedimentação para remover matéria sedimentável e turbidez das águas residuais. Os tanques de sedimentação podem ser ineficazes na redução da turbidez causada por pequenas partículas com gravidade específica baixa o suficiente para serem suspensas pelo movimento browniano descrito por Vander Kwaak e Loague (2019).

A Figura 6 apresenta o layout de duas bacias de decantação da Mina S III em que as bacias eram utilizadas para armazenar os resíduos líquidos produzidos na lavagem dos minérios. Esse resíduo, uma mistura de água e sedimentos carregados de metais, é despejado nas bacias de decantação.

Figura 6 - Bacias de decantação.

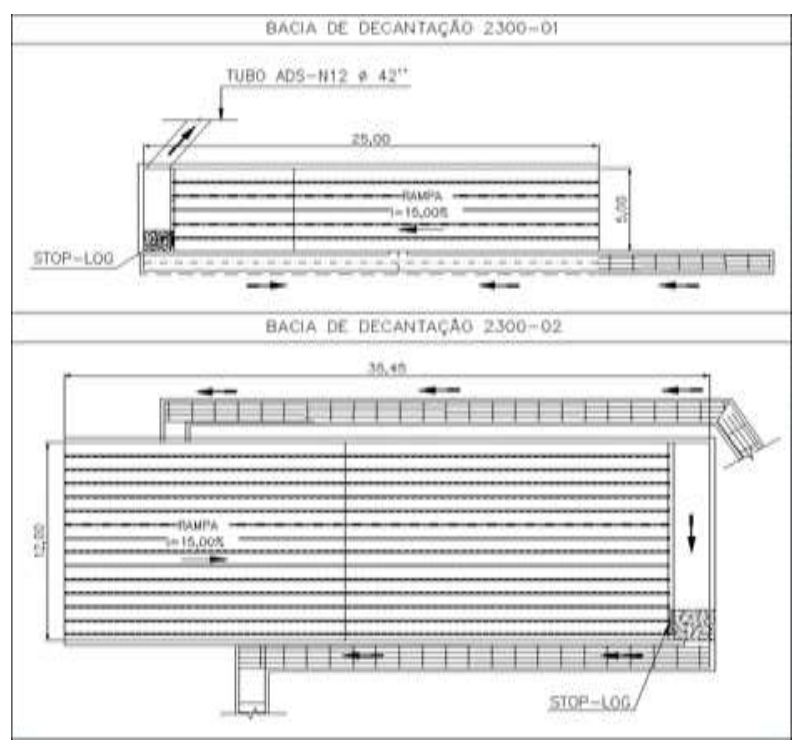

Fonte: Dados primários da pesquisa (2021).

Na definição da concepção do projeto procuraram-se soluções que minimizassem os impactos ambientais, as operações com rejeito/ canais de rejeito, os custos de implantação e, ao mesmo tempo, que fossem tecnicamente seguras. O lançamento do sistema de canalização será feito a céu aberto longe das dependências lindeiras ao canal do rejeito. A velocidade mínima adotada foi de $3,00 \mathrm{~m} / \mathrm{s}$; ademais, foi adotado seção mista para a seção do canal como mostra a Figura 7: 
Figura 7 - Arranjo do canal de Rejeito.

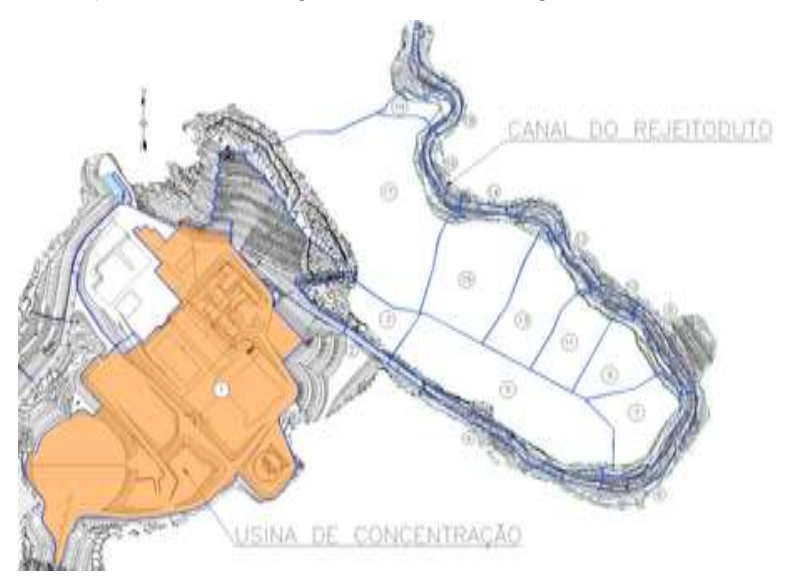

Fonte: Dados primários da pesquisa (2021).

A seção do canal foi definida através do somatório da contribuição máxima industrial (constantes e eventuais) + pluvial e o canal trabalhando em toda sua extensão com lâmina de água correspondente a um máximo de $85 \%$ de sua altura. Para os trechos em curva foi considerado uma lâmina de água correspondente a um máximo de $90 \%$ de sua altura quando houver a superelevação.

Para o dimensionamento canal rejeito com as contribuições industriais usina tem-se os dados apresentados no Quadro 3:

Quadro 3 - Valores das contribuições industriais da usina.

\begin{tabular}{|r|r|}
\hline Contribuições industriais da usina & Q $\left(\mathrm{m}^{3} / \mathrm{s}\right)$ \\
\hline CONSTANTE REJEITO SALOBO III $\left(0,53 \mathrm{~A} 1,46 \mathrm{~m}^{3} / \mathrm{s}\right)$ & 1,06 \\
\hline Eventual transbordo tanque de água recuperada & 0,14 \\
\hline Eventual transbordo do sump de emergencia & 1,40 \\
\hline Eventual transbordo prédio da recuperação de reagente & 0,10 \\
\hline Eventual transbordo estocagem e preparação de cal & 0,10 \\
\hline Eventual transbordo moagem de bolas & 1,40 \\
\hline Constante caixa cx-0101 sa-19 & 0,10 \\
\hline Contribuição total & 4,70 \\
\hline
\end{tabular}

Fonte: Dados primários da pesquisa (2021).

Observa-se que o projeto considerou o constante de rejeito; eventual transbordo de tanque de água recuperada e do sump de emergência; além de possível transbordo da recuperação do reagente e estocagem de preparação de cal; moagem das bolas e constante de caixa, cuja contribuição total foi de 4,70 Q (m3\s).

O Quadro 4 apresenta dos valores para contribuições totais: 
Quadro 4 - Contribuições industriais da usina - constantes e eventuais - Pluvial usina e pluvial canal.

\begin{tabular}{|c|c|c|c|c|c|c|c|c|c|c|c|c|c|c|c|c|c|}
\hline \multirow{4}{*}{ BACIAS } & \multirow{4}{*}{ TRECHO } & \multirow{4}{*}{ ESTACAS } & \multicolumn{9}{|c|}{ CANAL FUNCIONANDO NO CASO MAIS CRITITCO } & \multirow{2}{*}{\multicolumn{6}{|c|}{ CAPACIDADE HIDRÁULICA }} \\
\hline & & & \multirow[b]{2}{*}{$Q$} & \multicolumn{8}{|c|}{ DISPOSITIVO } & & & & & & \\
\hline & & & & \multirow{2}{*}{\begin{tabular}{|c|} 
Declividade \\
$(i \%)$
\end{tabular}} & \multicolumn{4}{|c|}{$\begin{array}{l}\text { RETANGULAR } \\
\text { Dimensões (m) }\end{array}$} & \multicolumn{3}{|c|}{$\begin{array}{l}\text { TRANGULAR } \\
\text { Dimensões (m) }\end{array}$} & & Área m. & \multirow{2}{*}{\begin{tabular}{|c|} 
Perím. m. \\
$(\mathrm{m})$
\end{tabular}} & \multirow{2}{*}{\begin{tabular}{|l|} 
Raio $h$. \\
$(\mathrm{m})$
\end{tabular}} & \multirow{2}{*}{\begin{tabular}{|c|}
$Q$ \\
$\left(\mathrm{~m}^{3} / \mathrm{s}\right)$
\end{tabular}} & \multirow{2}{*}{\begin{tabular}{|c|}
$\begin{array}{c}U \\
\text { (máx.) }\end{array}$ \\
s) \\
$(\mathrm{m} / \mathrm{s})$
\end{tabular}} \\
\hline & & & $\left(\mathrm{m}^{3} / \mathbf{s}\right)$ & & Larg. (B) & Lâmina & $\begin{array}{l}\text { Altura (h) } \\
\text { Adotado }\end{array}$ & \begin{tabular}{|c|} 
Altura (h) \\
$\%$
\end{tabular} & a & b & $\begin{array}{c}\text { Altura } \\
\text { (h) }\end{array}$ & "n" & $\left(m^{2}\right)$ & & & & \\
\hline $\mid$ INDUSTRIAL+1+2 & A & EST. $0+0,00$ A $8+15,00$ & 10,96 & 2,50 & 1,80 & 1,06 & 1,30 & 0,82 & 0,90 & 0,90 & 0,30 & 0,014 & 1,638 & 3,417 & 0,479 & 11,330 & 0 \\
\hline \begin{tabular}{|l|} 
INDUSTRIAL+1+2 \\
\end{tabular} & $A$ & EST. $8+15,00$ A $12+6,50$ & 10,96 & 3,00 & 1,80 & 0,98 & 1,20 & 0,82 & 0,90 & 0,90 & 0,30 & 0,014 & 1,494 & 3,257 & 0,459 & 10,993 & 37,36 \\
\hline$A+3+4$ & $B$ & EST. 12+6,50 A 21+16,00 & 11,75 & 3,00 & 1,80 & 1,04 & 1,30 & 0,80 & 0,90 & 0,90 & 0,30 & 0,014 & 1,602 & 3,377 & 0,474 & 12,055 & 557,52 \\
\hline$B+5+6$ & $c$ & EST. 21+16,00 A 31+4,00 & 12,31 & 3,00 & 1,80 & 1,11 & 1,30 & 0,85 & 0,90 & 0,90 & 0,30 & 0,014 & 1,728 & 3,517 & 0,491 & 13,310 & 107,70 \\
\hline$C+7+8$ & D & EST. $31+4,00$ A $43+16,00$ & 13,16 & 3,00 & 1,80 & 1,11 & 1,30 & 0,85 & 0,90 & 0,90 & 0,30 & 0,014 & 1,728 & 3,517 & 0,491 & 13,310 & 107,70 \\
\hline$D+9+10$ & $E$ & EST. $43+16,00$ A $50+18,00$ & 13,68 & 3,00 & 1,80 & 1,14 & 1,40 & 0,81 & 0,90 & 0,90 & 0,30 & 0,014 & 1,782 & 3,577 & 0,498 & 13,854 & 547,77 \\
\hline$E+11+12$ & $\mathrm{~F}$ & EST. $50+18,00$ A $54+18,00$ & 14,12 & 3,00 & 1,80 & 1,16 & 1,50 & 0,77 & 0,90 & 0,90 & 0,30 & 0,014 & 1,818 & 3,617 & 0,503 & 14,218 & \begin{tabular}{|l|l|}
87,82 \\
\end{tabular} \\
\hline$F+13+14$ & $G$ & EST. $54+18,00$ A $59+0,00$ & 14,48 & 3,00 & 1,80 & 1,18 & 1,50 & 0,79 & 0,90 & 0,90 & 0,30 & 0,014 & 1,854 & 3,657 & 0,507 & 14,583 & 337,87 \\
\hline$G+15+16$ & $\mathrm{H}$ & EST. $59+0,00$ A $65+0,00$ & 15,04 & 3,00 & 1,80 & 1,21 & 1,50 & 0,81 & 0,90 & 0,90 & 0,30 & 0,014 & 1,908 & 3,717 & 0,513 & 15,132 & 327,93 \\
\hline $\mathrm{H}+17+18$ & 1 & EST. $65+0,00$ A 71+0,00 & 15,83 & 3,00 & 1,80 & 1,25 & 1,50 & 0,83 & 0,90 & 0,90 & 0,30 & 0,014 & 1,980 & 3,797 & 0,521 & 15,869 & $\begin{array}{ll}998,01 \\
\end{array}$ \\
\hline $1+19+20$ & $\mathrm{~J}$ & EST. $71+0,00$ A $75+0,00$ & 16,94 & 3,00 & 1,80 & 1,31 & 1,60 & 0,82 & 0,90 & 0,90 & 0,30 & 0,014 & 2,088 & 3,917 & 0,533 & 16,982 & \begin{tabular}{|l|}
28,13 \\
\end{tabular} \\
\hline$J+21+22$ & $\mathrm{~K}$ & EST. $75+0,00$ A $85+5,00$ & 18,21 & 3,00 & 1,80 & 1,38 & 1,70 & 0,81 & 0,90 & 0,90 & 0,30 & 0,014 & 2,214 & 4,057 & 0,546 & 18,291 & 18,26 \\
\hline
\end{tabular}

Fonte: Dados primários da pesquisa (2021).

Os rejeitos das minas SI são transportados como polpa, algumas vezes em razão da gravidade mediante canais ou através de tubulações, com ou sem sistemas de bombeamento, conforme as elevações relativas entre a planta de beneficiamento e o local onde será descartado. A Figura 8 apresenta a seção do canal de rejeito da Mina SI:

Figura 8 - Arranjo do canal de rejeito da Mina S I.

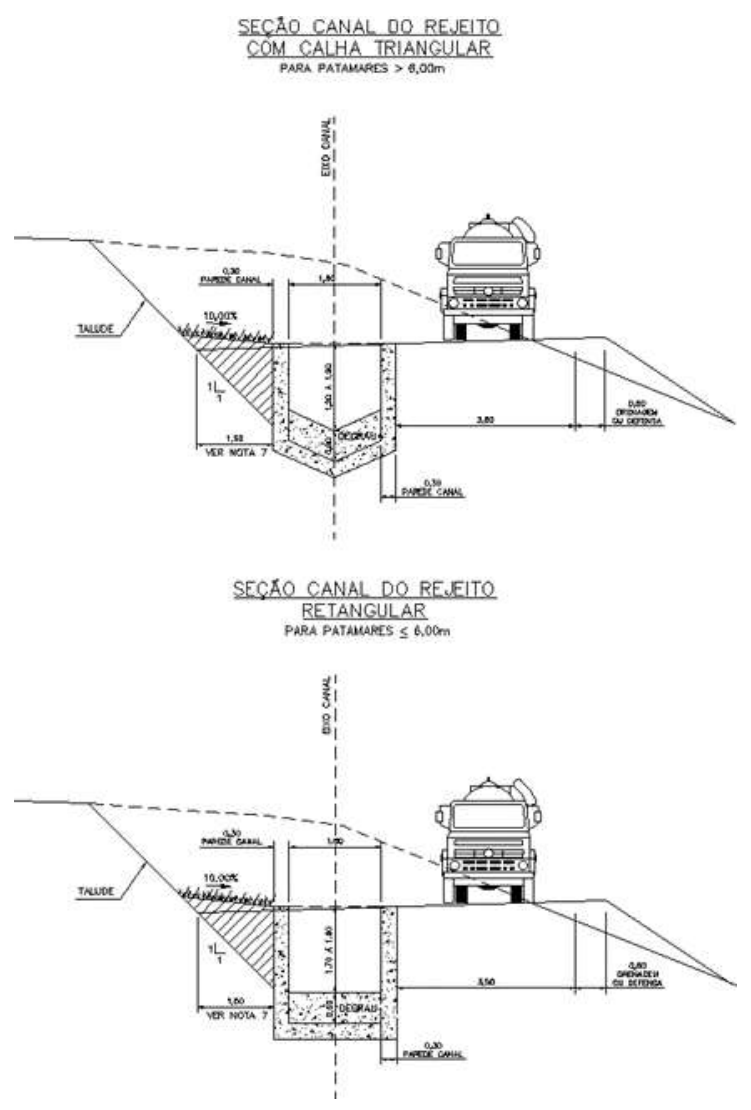

Fonte: Dados primários da pesquisa (2021).

O sistema de tubulação do canal de rejeito foi dimensionado baseando- se na velocidade mínima de fluxo demandada para evitar que as partículas no estado sólido do rejeito se sedimentem e obstruíssem a tubulação. A referida velocidade depende 
tanto da densidade da polpa, como do tamanho das partículas, oscilando em cerca de 1.5 a $3.0 \mathrm{~m} / \mathrm{s}$. A operação de britagem mostrada na Figura 9, foi também considerada no sistema de drenagem da Mina S I:

Figura 9 - Considerações sobre a operação de britagem 59.

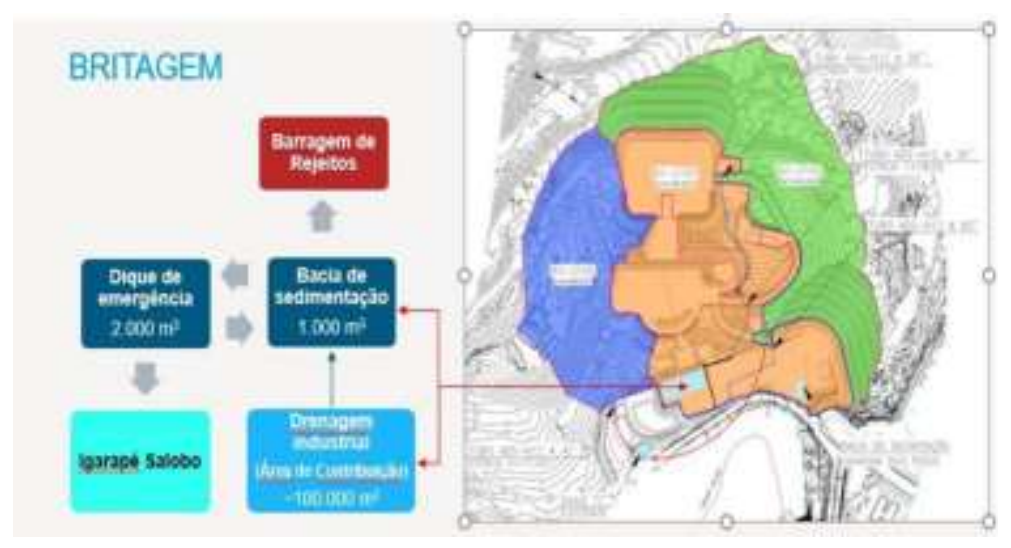

Fonte: Dados primários da pesquisa (2021).

O projeto foi desenvolvido de forma se evitar ao máximo a entrada de efluente proveniente das chuvas na região das contenções por sob a correia. A drenagem pluvial foi totalmente segregada da drenagem contaminada. A Figura 10 representa a caixa de retenção de sedimentos adotada na Mina SI.

Figura 10 - Exemplo de caixa de retenção.

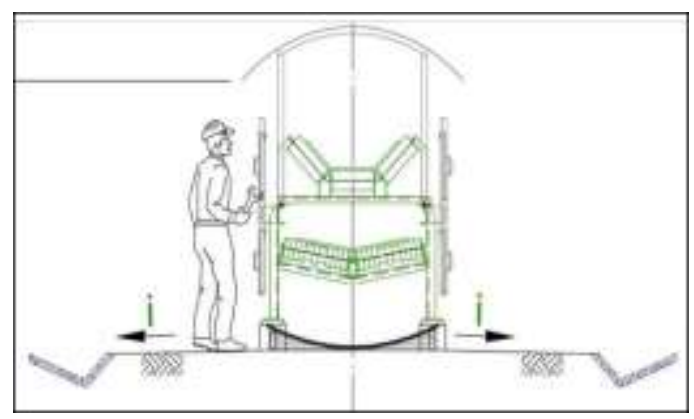

Fonte: Dados primários da pesquisa (2021)

Na Figura 11 se tem a visão da caixa de retenção CR - E- 02B escavada no solo, permitindo que a drenagem superficial entre e decante os sólidos arrastados. 
Research, Society and Development, v. 10, n. 16, e295101623790, 2021

(CC BY 4.0) | ISSN 2525-3409 | DOI: http://dx.doi.org/10.33448/rsd-v10i16.23790

Figura 11 - Dimensão da caixa de retenção CR - E- 02B.

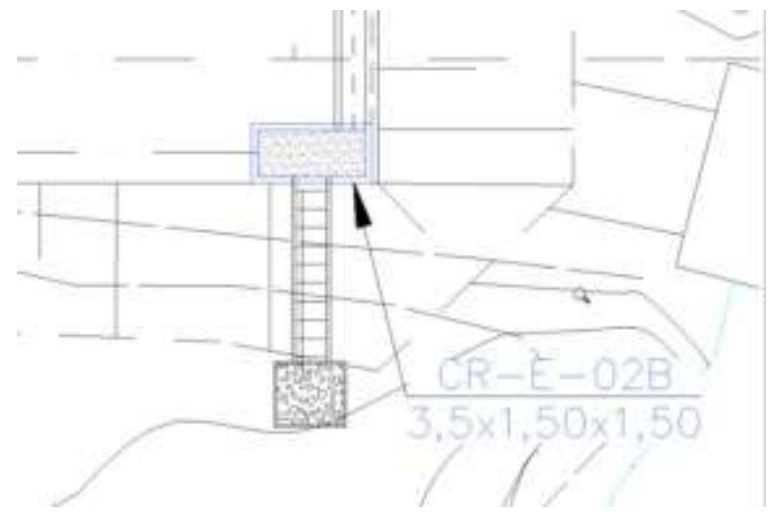

Fonte: Dados primários da pesquisa (2021).

Na Figura 12 se tem uma visão do escoamento da água dentro da caixa de retenção podendo ocorrer em degraus ou por canaleta:

Figura 12 - Descida da água no interior da caixa de retenção.

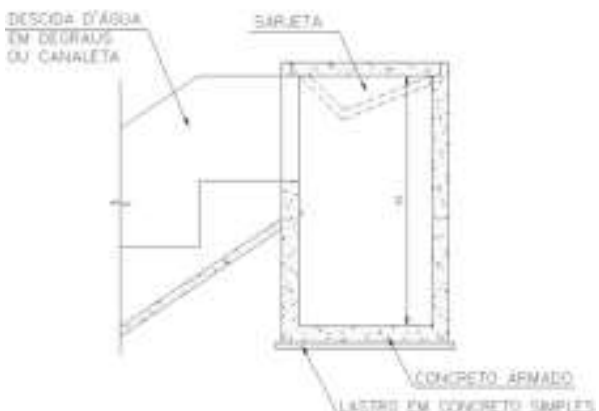

Fonte: Dados primários da pesquisa (2021).

No Quadro 5 se os dados para o projeto de um sistema de drenagem de água da chuva para coletar o escoamento de água e proteger as estruturas existentes, bem como para evitar danos às casas como consequência de chuvas extraordinariamente altas. Especificamente, o sistema de drenagem de águas pluviais foi considerado para captar e conduzir a água da chuva até o corpo receptor projetado para tal fim. 
Quadro 5 - Elementos estruturantes do Projeto detalhado S I.

\begin{tabular}{|c|c|c|c|c|c|c|c|c|c|c|c|c|c|c|c|}
\hline \multicolumn{16}{|c|}{ 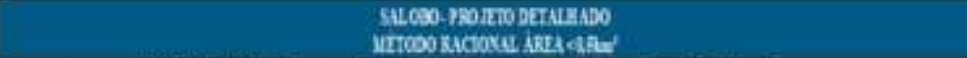 } \\
\hline \multirow{2}{*}{ rach } & \multirow{2}{*}{ EstaCa } & \multicolumn{2}{|c|}{ IREA 1} & \multirow{2}{*}{\begin{tabular}{|l|} 
IfRed 2 \\
$\mathrm{kn}^{\prime} / \mathrm{hu}$ \\
\end{tabular}} & \multirow{2}{*}{\begin{tabular}{|l|} 
L \\
(ni) \\
\end{tabular}} & \multirow{2}{*}{$\frac{\mid+1}{|n|}$} & \multirow{2}{*}{$\frac{1}{n+m}$} & \multirow{2}{*}{$\mathrm{Cl}$} & \multirow{2}{*}{ ar } & \multirow{2}{*}{\begin{tabular}{|l|l|} 
Eical \\
inini \\
\end{tabular}} & \multicolumn{2}{|c|}{ Iinm:h] } & \multicolumn{2}{|c|}{$\theta\left(\min ^{2}\right)$} & \multirow{2}{*}{ SECAOD DO BUERO (n) } \\
\hline & & & & & & & & & & & \multicolumn{4}{|c|}{ 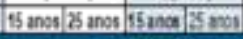 } & \\
\hline \multicolumn{16}{|c|}{ 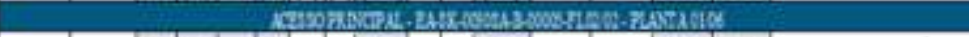 } \\
\hline 510000 & $9 \cdot 5$ & 205 & Q85: & 20 & 35 & 24 & 2.10 & 070 & & tas & $24 x$ & 2309 & 05 & $0 \mathbf{2}$ & RUBO, $/ 05-N 12037$ \\
\hline BQ01030 & $14+10$ & 2003 & DEA & 28 & 115 & 25 & 2211 & 070 & & 1 焉 & 248 & 200 & 00 & 8.6 & TUEOAOS.N12 O36 \\
\hline Bano & $24+19$ & 0,0 & 13 . & 20 & 79 & 69 & 028 & 0.45 & & 988 & 248 & 2005 & 04 & 16 & RUBO ACSAII OIS \\
\hline \multicolumn{16}{|c|}{ 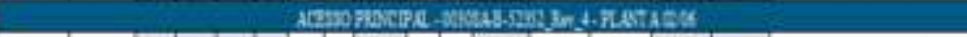 } \\
\hline B40030 & $36+15$ & 900 - & 380 & 200 & 30 & 7i: & 0.86 & 0.45 & & 231 & 242 & 2309 & 127 & 10 & RUBOACSNII OLT \\
\hline 850000 & $8+0$ & 2002 & 324 & 10 & 歏 & 8 & 0.80 & 0.65 & & $22 \pi$ & 248 & 230 & 109 & 114 & TRBOAOS.N12 O3F \\
\hline Benos & $5+172$ & 2009 & 549 & 20 & s8 & 198 & lox & 0.45 & & 221 & 248 & 200 & 112 & 20 & BSCC1sariso \\
\hline \multicolumn{16}{|c|}{ 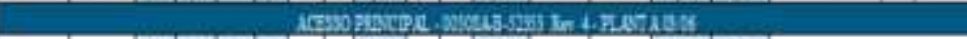 } \\
\hline B7t2000 & $61 \cdot 500$ & 100 & 46? & 8 & 1084 & 92 & 213 & 045 & & 150 & $\ln 34$ & 221 & 29 & 28 & REOACS-N12 OSF \\
\hline Benow0 & 6.000 & 3xt & $0,2$. & 28 & 119 & 30 & $\$ 28$ & 070 & & 131 & 242 & 2009 & as & A3 & RUBO AOS-N12 O3S \\
\hline BQ0010 & $34+400$ & 2000 & 273 & 200 & 218 & 50 & $\log$ & 070 & & 2003 & 248 & 2009 & 19 & 19 & 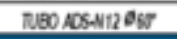 \\
\hline \multicolumn{16}{|c|}{ 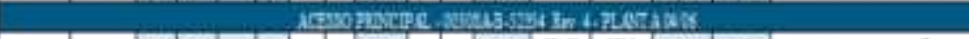 } \\
\hline B10,0E0 & 104000 & exs & 275 & 20 & 213 & 34 & 0,89 & Q70) & & 183 & 248 & 2309 & 19 & 18 & REO ACSNII OLF \\
\hline Bt1200 & 11405 & 2005 & 34 & 20 & 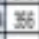 & 战 & 0.26 & 070 & 2,45 & 266 & 248 & 2009 & 23 & $2 E$ & REO ACSNA12 OSF \\
\hline B120050 & 124000 & 2150 & 5.37 & 200 & 54 & 20 & 20 & 0.65 & & 167 & 248 & 208 & 58t & 59 & TUBO ACS-N12 $\theta_{6} \mathrm{~F}$ \\
\hline B1300: & $17+470$ & $9 x$ & 115 & 20 & 100 & 8 & 012 & 0.45 & & $3 x:$ & 200 & 220 & 19 & 10 & BSCC2 $2 \times n=0$ \\
\hline
\end{tabular}

Fonte: Dados primários da pesquisa (2021).

As redes tubulares de drenagem foram dimensionadas, em correspondências às descargas de projeto, estabelecidas nos Estudos Hidrológicos. Foram especificadas obras cujas descargas máximas permissíveis, atendem, com flexibilidade, às descargas ocorrentes. As descargas permissíveis, definidas para as obras foram limitadas pelas condições: carga energética a montante correspondente à elevação do nível d'água a uma cota acima do fundo da seção máxima igual a 80 \% do diâmetro (condição de máxima vazão), para redes tubulares e de $80 \%$ para as galerias celulares; a declividade da rede estará situada entre os seguintes patamares: a declividade deverá ser inferior àquela capaz de determinar velocidade máxima (8 m/s) , acima da qual tem início a instalação de processo erosivo nas paredes do concreto; a declividade deverá ser superior àquela capaz de evitar deposição de material sólido no fundo das redes. Para as vias e talvegues transversais, onde necessário, ou seja, quando a vazão exigiu, projetaram-se redes tubulares, galerias celulares e bueiros que possibilitaram a interligação com a canalização projetada. Os projetos de canalização e drenagem são apresentados em prancha única, juntamente com perfis e detalhes.

O sistema de drenagem projetado para as vias adjacentes ao talvegue a ser canalizado, aproveita parcialmente redes e dispositivos de drenagem existentes, anexando-os nos novos trechos projetados, e por outro lado prevê demolição naqueles trechos onde foi verificada a insuficiência dessas redes ou em casos de incompatibilidade de cotas com a canalização projetada, substituindo-as

\section{Considerações Finais}

Este estudo considerou as principais características de um projeto de drenagem pluvial para serviços e atividades básicas de uma planta de beneficiamento mineral essenciais à melhoria das condições da própria atividade mineradora e da população do entorno. Foi possível compreender de acordo com os autores selecionados para a revisão teórica, que este serviço deve contemplar não somente a compreende a distribuição de água em quantidade e qualidade adequadas a operacionalização da mina SI, mas também a coleta e remoção das águas residuárias e de escoamento superficial da área ocupada pelas áreas de operacionalização, além da coleta e acondicionamento final dos rejeitos.

No contexto da implantação do sistema de drenagem pluvial na Mina S I, em função de sua importância, foi observado e tratado como prioridade, os aspectos na infraestrutura, considerando-se que o bom funcionamento desses serviços implicando diretamente em operação mais segura das atividades de tratamento do rejeito de minérios bem como atividades correlatas ao seu beneficiamento, como a etapa da britagem. Pôde-se verificar que a eficiência do sistema de drenagem pluvial para a Mina SI 
mostrou-se com resultado conclusivo, respeitando o período de observação adequado, fundamentando a construção dos elementos estruturantes do sistema de drenagem para esta unidade e avaliando a sua dinâmica no período de maior intensidade de precipitações.

Ficou evidenciada a importância e a necessidade de se contar com um projeto de sistema de drenagem, considerando alguns recursos necessários já existente na Mina SI, devendo havendo deste modo, um alinhamento para elaboração e adequação da atividade na rotina do empreendimento.

Sugerem-se estudos futuros que possam comparar diferentes propostas de drenagem pluvial em contextos distintos, com medidas estruturantes e não estruturantes, a fim de estabelecer um intercâmbio de tecnologias; métodos construtivos e alternativas em termos de materiais e soluções para minas a céu aberto e sistemas de drenagem pluvial.

\section{Referências}

Awasthi, B. (2019), Analyzing the effect of distribution pattern \& number of GCPs on overal accuracy of UAV photogrammetric results. International Conference on Unmanned Aerial System in Geomatics.

Araújo, C. E. Da S. Schuster, H. D. M., \& Lima, A (2011). Modelagem e simulaçãonumérica do processo de drenagem em mina a céu aberto. XV Congresso Brasileiro de Águas Subterrâneas. 1, 32-6 Ouro Preto-MG.

Barros, D. A. D., Guimarães, J. C. C., Pereira, J. A. A., Borges, L. A. C., Silva, R. A., \& Pereira, A. A. S. (2012) Characterization of the bauxite mining of the Poços de Caldas alkaline massif and its socio-environmental impacts. Rem:Revista Escola de Minas, 65(1), $127-133$.

Castro, L. M., Barros, D. A. \& Pereira, A. A. S (2009). Monitoramento de Águas Superficiais em Área de Explotação de Bauxita, no Planalto de Poços de Caldas, Minas Gerais. Revista Científica Aprender, 13(1), 72-94.

Costa, E. M., Samuel-Rosa, A. \& Anjos, L.H.C. (2018). Digital elevation model quality on digital soil mapping prediction accuracy. Ciência e Agrotecnologia, 42(6), 608-622, 2018.

David, H. (2014). Controle das águas em projetos de mineração. 2014.https://www.maxwell.vrac.puc-rio.br/24815/24815_4.PDF.

Franco, E. J. (2004) Dimensionamento de Bacias de Detenção das Águas Pluviais com Base no Método Racional. 2004. Dissertação (Mestrado em Engenharia de Recursos Hídricos e Ambiental). Universidade Federal do Paraná,Curitiba.

Gonçalves, L. E. S. (2018). Eficência do sistema de drenagem adotado na região de mineração de bauxita, na zona da mata de Minas Gerais. Dissertação. Universidade Federal de Viçosa. Programa de Pós- Graduação em Ciência Florestal para obtenção do título Magister Scientiae.

Langhammer, J. (2019), UAV monitoring of stream restorations. Hydrology, 6(29), 29.

Lin, C. A., L. Wen, G. H. Lu, Z. Y. Wu, J. Y. Zhang, Y. Yang, Y. F. \& Zhu, L. Y. T, (2020) Atmospheric-hydrological modeling of severe precipitation and floods in the Huaihe River Basin, China. J. Hydrol., 330, 249-259

Loura, D. S. (2011). Levantamento e Conservação do Solo: práticasconservacionistas de solos e águas. Terraceamento agrícola, UFLA, 2011.

Marques, G. S. ( $\left.\begin{array}{llll}2 & 0 & 1 & 9\end{array}\right)$ Manejo de Águas pluviais: estudo da rede drenagem e de soluções de baixo impacto na Região Administrativa. Candangolândia. Distrito Federal.

Polat, N. \& Uysal, M. (2018) An experimental analysis of digital elevation models generated with Lidar Data and UAV photogrammetry. Journal of the Indian Society of Remote Sensing, 46(7), pp. 1135-1142.

Rock, G., Ries, J. B. \& Udelhoven, T. (2020). Sensitivity analysis of UAV-photogrammetry for creating digital elevation models (DEM). In: Proceedings of the Conference on Unmanned Aerial Vehicle in Geomatics, Zurich, Switzerland, 1416.

Silwamba, C. \& Chileshe, P. R. K. (2015). Risk Evaluation and Mitigation Measures for Slope Management at Chingola Open Pit D\&F Zambia. Symposium Series S83: Copper Cobalt Africa 2015 - 8th Southern African Institute of Mining and Metallurgy Base Metals Conference, 21 - 32, 6 8th July 2015, Livingstone, Zambia. Johannesburg, South Africa: The Southern African Institute of Mining and Metallurgy, ISBN 978-1-920410-71-1

Silveira, L. M. (2014). Drenagem em minas de bauxita na região de poços de caldas. Trabalho de Graduação, Universidade Federal de Alfenas, Alfenas, Brasil, p.32.

Teixeira Júnior, Paulo Borges. (2015) Estudos de drenagem superficial aplicados às minas a céu aberto. https://inis.iaea.org/collection/NCLCollectionStore/_Public/17/087/17087445.pdf

Thompson, R.J, Peroni R.L. \& Visser, A.T. (2019). Mining Haul Roads: Theory and Practice. CRC Press, UK, 316 P.

Tucci, C.E.M (2013). Gerenciamento da Drenagem Urbana. Pinni.

VanderKwaak, J. E., \& K. Loague (2019): Hydrologic-response simulations for the R-5 catchment with a comprehensive physics-based model. Water Resour. Res., 37, 999-1013 